\title{
What we were reading in 2018
}

Following on from last year's editorial 'What we're reading' (Hyslop, Hay, \& Beddoe, 2018) we've included the same analysis as 2018 in this editorial. The selection of the top 15 most read, identified by the web analytics, are presented here thematically. All of these articles are available on the journal website, open access and free to download from our archives. First up is a group of four articles published in the Te Komako issues, which always feature regularly in the top reads, as they should, reflecting Māori writing.

In the first of the Te Komako selection, Jacquelyn Elkington's article, 'A Kaupapa Māori supervision context—cultural and professional,' affirms an indigenous perspective for Māori practitioners of professional supervision particularly in the practice of Kaupapa Māori supervision. Based on research conducted for her PhD study of Kaupapa Māori supervision completed in 2013, Elkington explores the challenges for cultural supervision, deconstructing these by questioning existing power relations within the social services sector. The article reports some key solutions including visibility of mono-cultural values in western origin models of supervision and the revival and creation of more Kaupapa Māori supervision models within safe and protected environments. Elkington also recommends that Kaupapa Māori research methodology underpins future developments.

In 'Theories in Māori social work: Indigenous approaches to working with and for indigenous people,' Awhina Hollis-English (2015) explores how Māori social work practice has been developed upon a strong underpinning of indigenous knowledge, theories and values. Hollis-English describes selected Māori social work theories and explores how they have developed within the social work world and how they can validate social work practice. A number of theories have been described by Māori social workers from across Aotearoa as the foundations for their social work practice. Theoretical discourse in the world of Māori enables practice development for Māori social workers, "leaning on ancestral knowledge and valuing the skills that are gained through understanding tikanga in a contemporary context" (p. 5).

'The teaching of Māori social work practice and theory to a predominantly Pākehā audience' is the title of Shayne Walker's 2012 article. Walker explores the practices of teaching Aotearoa New Zealand social work students to prepare them for bicultural practice including te reo Māori and tikanga alongside specific teaching on the importance of Te Tiriti o Waitangi for social work practice. Walker suggests strategies for moving forward to help social work students feel more confident in practices in a bicultural setting. Walker notes that taking a cross-cultural position poses some difficulties as most diversity and crosscultural models emerge from western rather than indigenous frameworks and thus there is a need to integrate indigenous methods and worldviews.

Paora Moyle's (2014) article, 'A model for Māori research for Māori practitioners,' presents a Māori model for research that draws strongly from Kaupapa Māori theory and principles, using qualitative methods. Moyle explores Kaupapa Māori epistemology and its influences on her entire research project from the development of the topic to the analysis stage, and the importance of giving back to Māori social work participants and the wider community. Referencing Linda Smith's work on decolonising research (1999) Moyle describes "Kaupapa Māori as a 'home grown' form of critical theory that focuses on emancipation" which refers to a "framework or methodology for thinking about and undertaking research by Māori, with Māori, for the benefit of Māori ... It is a way of
AOTEAROA

NEW ZEALAND SOCIAL WORK 31(2), 1-6. 
understanding and explaining how we know what we know and it affirms the right of Māori to be Māori' (pp. 29-30).

In the next section, practice features strongly with five articles focusing on practice matters.

In one of the three older articles in this selection, 'Preliminary comparison between the roles of support workers and social workers in community mental health services' Barnaby Pace (2009) explores the issue of confusion between paraprofessionals, such as support workers, and professionals, including social workers which could lead to conflict in the workplace. Pace hypothesises that, if support workers were recognised more appropriately for the work they do, there would not be the conflict that currently appears present between these two disciplines. This research identified differences in the level of qualification, requirements for registration alongside specific competencies, and the performance of clinical work such as referrals, assessment, information collection and report writing which featured strongly in social work job descriptions. Pace recommends that future research be focused on determining the function and relationship of these two disciplines before developing associate social worker status for support workers, an important debate considering the possibilities of regulation of support workers in the near future.

In another article focusing on the mental health sector, Kathy Martindale, a quality of life (QOL) researcher and Ross Phillips a social worker and mental health consultant, argue that a QOL framework applied in social work practice would assist to determine an evidence base that achieves current "mental health policy ambitions of recovery, inclusion and community care, whilst also providing mental health social work a clear description of role and function" (Martindale \& Philips, 2009, p. 56). Exploring concepts such as recovery and subjective wellbeing, this article sets out conditions for practice in which holistic aspects of a person's life are centred including environmental, cultural and social interconnections. Understanding social and community contexts is particularly important in moving beyond limited medical responses.

'Changing landscapes: Responding to domestic violence in New Zealand' by Yvonne Crichton-Hill (2010) discusses the complexity of social work in domestic violence. Crichton-Hill advises practitioners to be both cautious and creative in their work with women. She argues successful social work requires recognition of the uniqueness of each woman while being cognisant of the social and political forces that have contributed to her situation. The article explores the causal explanations and contextual factors that have shaped Aotearoa New Zealand's social work response to domestic violence. A research-informed, multifaceted, anti-discriminatory approach to practice is proposed.

In 'Incorporating community development into social work practice within the neoliberal environment' Jenny Aimers and Peter Walker (2011) explore community development practice within the context of a community and voluntary sector social services. Their aim is to identify ways that social workers might 're-embed community development within their practice while also resisting the dominant neoliberal political discourse' (p. 39). They are concerned that the government of the day had marginalised community development and use the term to describe activities that were top-down rather than coming from the flax roots.

In 'Social work with older adults in primary health-is it time to move our focus?'

Sue Foster and Liz Beddoe (Foster \& Beddoe, 2012) discuss the need for better provision of social work support, including psychosocial interventions, advocacy and risk assessment for older adults in their 
homes and residences. They argue that social work in the 21st century needs to establish a presence in the primary care community where their skills would be well utilised. They recommend that research be undertaken in New Zealand to explore the potential for, and likelihood of, acceptance by all stakeholders of a social work service provided at the primary care interface with individuals, families and communities in New Zealand.

The final selection of articles all focus on the profession itself. Also amongst the 2017 top reads, Elizabeth Hobbs' and Nikki Evans' article 'Social work perceptions and identity: How social workers perceive public and professional attitudes towards their vocation and discipline' reports on the fight for recognition of social work's professional status. Social work identity and public perceptions remain strong themes and, given the very public debates about social work in 2019 , it would be interesting to explore some of these again, especially the influence of statutory child protection on social work identity, professional marginalisation in multidisciplinary teams and the impact of mandatory registration of social workers.

Matt Rankine (2017), in 'Making the connections: A practice model for reflective supervision,' describes a new model of reflective supervision arguing for an approach to community social work supervision that is grounded in a co-constructed partnership between the supervisor and supervisee. Rankine presents a four-layered model to support critical thinking in the diverse socio-political and cultural contexts of social work and promotes social justice strategies.

Mike O'Brien's research (2009) is based on ANZASW members' responses to a questionnaire describing their approach to social justice and the links between social justice and their practice. 'Social work and the practice of social justice: An initial overview' provides an initial summary of social workers' thinking about and approach to social justice in their practice. $\mathrm{O}^{\prime}$ Brien found that social justice talk occurs much more in the context of individual examples than in broader social policy considerations. The significant finding is that these practitioners frame social justice primarily, and 'almost entirely, about individual actions aimed at more socially just outcomes and experiences for users (p. 9).

Another article that was in the top read in 2017, appears again. Petro Booysen and Barbara Staniforth's (2017) article on counselling as an element of social work explores the legitimate function of counselling in social work in Aotearoa New Zealand finding that social workers regularly use counselling skills. They argue that rigid boundaries between the two professions can have adverse effects for clients at times when multi-skilled professionals are needed. This is an enduring issue and this article retains durable interest from our readers.

Heidi Crawford's (2016) article on being a Pākehā social worker features again in the top reads of 2018. Crawford's personal reflective narrative recounts her journey as a Pākehā towards bicultural practice. In a deeply reflective piece, of great value for students and beginning social workers, Crawford shares her discovery of loss of identity as Pākehā and encourages other Pākehā to connect with who has gone before them in an attempt to understand self and understand others and move towards compassion and hope.

Finally, Rebecca Giles' (Giles, 2016) research report on social workers' perceptions of multi-disciplinary team (MDT) work in major regional hospital in Aotearoa New Zealand has attracted a solid readership. Giles finds that social workers consider that effective and well-facilitated MDTs are very important in supporting the non-medical aspects of patient care. But, 
where MDTs do not function well and social work and patient concerns with wider, nonmedical issues are devalued, outcomes are less satisfactory for patients.

\section{The current issue}

Our most read articles of 2018 demonstrate the enduring interest in local research. This new issue of Aotearoa New Zealand Social Work reflects the growing international contribution to the journal and, in doing so, reminds us that, while we practise in many different and diverse locations, there are some common concerns that occupy the minds of practitioners, researchers, and scholars. This issue includes contributions from Aotearoa New Zealand, Australia, Scotland, England and Sweden.

In 'An invisible population-Young carers in Aotearoa New Zealand,' Sue Hanna and Charlotte Chisnell discuss the circumstances of young carers, a population of children, young people and young adults who are often socially isolated and who have received little attention social policy, social work practice and research in Aotearoa New Zealand. The authors review the literature and reflect, as two Englishregistered social workers, now educators in Aotearoa New Zealand, on practice with young carers in the United Kingdom. Chisnell and Hanna use a children's rights framework to advocate that greater attention should be paid to understanding the complexity of these young carers' roles and their rights as children under the United Nations Convention on the Rights of the Child.

The Counter-Terrorism and Security Act (2015) passed in the United Kingdom (UK) made it mandatory for social workers, as well as a wide range of caring professionals, to work within the PREVENT policy, originally introduced in 2002, as one strand of the UK's overall counter-terrorism policy. In 'PREVENT, safeguarding and the common-sensing of social work in the United Kingdom', David McKendrick (Scotland) and Jo Finch (England) theorise the concept of common sense and how complex issues such as terrorism can be reduced to a series of assertions, claims and panics that centre on the notion of common sense. Programmes such as PREVENT co-opt social workers into an increasingly securitised environment via a significant linking of traditional safeguarding social work practice with counter-terrorism activity.

Alternative, or non-traditional, approaches to responding to oppression and injustice are increasingly sought in social work. In 'Banging the same old colonial drum? Moving from individualising practices and cultural appropriation to the ethical application of alternative practices in social work,' Canice Curtis and Christine Morley explore the application of group drumming practices within social work. Curtis and Morley use critical reflection to explore the ethical challenges of incorporating cultural practices into social work and highlight strategies that support cultural humility.

The assessment of the suitability of social work students for future practice is often a fraught aspect of social work education. In 'Social work students' feedback about students' suitability for field education and the profession,' Ines Zuchowski, Sally Watson, Tracey Dickinson, Nicole Thomas and Sandra Croaker report on a Queensland study conducted with final-year social work students which examined their ideas about suitability and unsuitability for field education and practice. The article reports that students identify a "critical understanding of self, skills, knowledge, attitudes and contextual factors" as vital and with indicators of unsuitability including "lack of preparedness to learn, lack of capacity to demonstrate an understanding of professional values and ethics and inability to maintain professional boundaries or demonstrate basic practice skills". Students make suggestions for further development of an assessment model.

This issue contains one Research Brief article, by Michael Wallengren Lynch, a 
social work educator teaching in Sweden. In another article on social work education 'Teachers' experiences of student feedback: A view from a department of social work in Sweden,' Wallengren Lynch reports on a study designed to explore how teachers in a department of social work engage with, and manage, student feedback on their teaching methods and approaches. Internationally there is a growing, yet underdeveloped, interest in understanding the emotional impact of student feedback, and how it contributes to pedagogical self-development. It is reported that some teachers experience negative emotions regarding feedback that was unpleasant but had developed strategies to deal with the feedback.

\section{Viewpoints}

There are two Viewpoint articles in this issue. In 'Social work and social justice: The relationship between fitness to practise and criminal convictions for non-violent activism' Nathan J. Williams, addresses an often-discussed aspect of social work education and professional registration, the matter of criminal convictions gained by those who are engaged in non-violent social justice activism (NVSJA). Williams points out that current "fit and proper" rules under the new Social Workers Registration legislation create a potential barrier for social workers "who go beyond the rhetoric and fight for social justice, in a macro and practical sense," from gaining registration. This does not sit well with the ethical obligations we have under the statements of our professional bodies (local and international) to uphold and strive for human rights and social justice. Williams makes a strong case for reviewing the current policy to align it better with international requirements of social workers.

In 'Overseas social work placements: Can a well-designed workflow contribute to the success of an overseas placement?' Lee Henley, Simon Lowe, Zoe Henley and Claudia Munro reflect on the importance of workflow design for students completing field education in their social work degree. Specifically, this article examines this in the context of an Aotearoa New Zealand social work student completing a final placement at a non-governmental organisation (NGO) in Battambang Cambodia, Children's Future International (CFI). The article describes the advantages of designing an overseas placement approach which is planned to flow from theory development to practice implementation.

\section{References}

Aimers, J., \& Walker, P. (2011). Incorporating community development into social work practice within the neoliberal environment. Aotearoa New Zealand Social Work, 23(3), 38-49. doi:10.11157/anzswjvol23iss3id159

Booysen, P., \& Staniforth, B. (2017). Counselling in social work: A legitimate role? Aotearoa New Zealand Social Work, 29(1), 16-27. doi:10.11157/anzswj-vol29iss1id214

Crawford, H. S. (2016). A Pākehā journey towards bicultural practice through guilt, shame, identity and hope. Aotearoa New Zealand Social Work, 28(4), 80-88. doi:10.11157/anzswj-vol28iss4id300

Crichton-Hill, Y. (2010). Changing landscapes: Responding to domestic violence in New Zealand. Aotearoa New Zealand Social Work, 22(4), 12-19. doi:10.11157/ anzswj-vol22iss4id31

Elkington, J. (2014). A Kaupapa Māori supervision contextcultural and professional. Aotearoa New Zealand Social Work, 26(1), 65-73.

Foster, S., \& Beddoe, L. (2012). Social work with older adults in primary health-is it time to move our focus? Aotearoa New Zealand Social Work, 24(2), 37-48.

Giles, R. (2016). Social workers' perceptions of multidisciplinary team work: A case study of health social workers at a major regional hospital in New Zealand. Aotearoa New Zealand Social Work, 28(1), 25-33. doi:10.11157/anzswj-vol28iss1id113

Hobbs, E. K., \& Evans, N. (2017). Social work perceptions and identity: How social workers perceive public and professional attitudes towards their vocation and discipline. Aotearoa New Zealand Social Work, 29(4), 19-31. doi:10.11157/anzswj-vol29iss4id378

Hollis-English, A. (2015). Theories in Māori social work: Indigenous approaches to working with and for indigenous people. Aotearoa New Zealand Social Work, 27(4), 5-15. doi:10.11157/anzswj-vol27iss4id432

Hyslop, I., Hay, K., \& Beddoe, L. (2018). Editorial: What we're reading. Aotearoa New Zealand Social Work, 30(1), 1-6. doi:http://dx.doi.org/10.11157/anzswj-vol30iss1id494

Martindale, K., \& Phillips, R. (2009). Applying quality of life in mental health social work practice. Aotearoa New Zealand Social Work, 21(4), 55-63. doi:10.11157/ anzswj-vol21iss4id261

Moyle, P. (2014). A model for Māori research for Māori practitioners. Aotearoa New Zealand Social Work, 26(1), 29-38. doi:10.11157/anzswj-vol26iss1id52 
O'Brien, M. (2009). Social work and the practice of social justice: An initial overview. Aotearoa New Zealand Social Work, 21(1\&2), 3-10.

Pace, B. (2009). Preliminary comparison between the roles of support workers and social workers in community mental health services. Aotearoa New Zealand Social Work, 21(3), 33-37. doi:10.11157/anzswj-vol21iss3id273

Rankine, M. (2017). Making the connections: A practice model for reflective supervision. Aotearoa New Zealand Social Work, 29(3), 66-68. doi:10.11157/anzswjvol29iss3id377

Smith, L. T. (1999). Decolonising methodologies research and indigenous people. Dunedin, NZ: University of Otago Press.

Walker, S. (2012). The teaching of Māori social work practice and theory to a predominantly Pākehā audience. Aotearoa New Zealand Social Work, 24(3-4), 65-74. doi:10.11157/anzswj-vol24iss3-4id125

Liz Beddoe for the Editorial Collective, September 2019 